\title{
The Influence of a University's Social Identity on NCAA Divisional Affiliation
}

\author{
Dylan P. Williams \\ The University of Alabama \\ Chad Seifried \\ Louisiana State University \\ Brian P. Soebbing \\ Temple University
}

\begin{abstract}
Several scholars noted universities changing their intercollegiate athletic association are influenced by rival schools with similar social identities (Smith, 2011; Smith, Williams, Soebbing, \& Washington, 2013; Washington, 2004, 2004-05; Weaver, 2010). Specifically, most of these studies reviewed institutions that were former members of the NAIA and moved to the NCAA since 1973, noting university officials affiliated with the NAIA considered the organization as a detriment to their own firm's identity (Smith, 2011; Washington, 2004-05). Thus, many of these universities departed the NAIA to join the NCAA. However, NCAA affiliation requires institutions to review NCAA rules and regulations to determine which division best suit their respective school's needs (i.e., Division II or III). Thus, the purpose of this study was to determine if a school's many social identities influence the likelihood of movement from the NAIA to either Division II or Division III. The results from a logistic regression model showed schools located in the Southeast region of the United States, designated as an HBCU or a women's college, considered a small or a large school according to the Carnegie Foundation or sponsor women's basketball are more likely to leave the NAIA for Division II. Schools located in the Great Lakes region or affiliated with a Mainline Protestant denomination have higher tendencies to leave the NAIA for Division III. These results could assist the NAIA in the recruitment of new members and talk to current members possessing these identifies to create new mechanisms to retain their NAIA affiliation.
\end{abstract}

Keywords: Social Identity Theory, social mobility, NCAA division

\footnotetext{
Williams is with the Department of Kinesiology at The University of Alabama, Tuscaloosa, AL. Seifried is with the School of Kinesiology at Louisiana State University, Baton Rouge, LA. Soebbing is with the School of Tourism and Hospitality Management at Temple University, Philadelphia, PA. Address author correspondence to Dylan Williams at dwilliams1@bamaed.ua.edu.
} 
Traditionally, scholars have analyzed organizations based on the concepts and tools developed by economists (Washington \& Zajac, 2005). However, more management researchers have used institutional theory to explore a firm's social foundations to determine its success in relation to its competitiveness and market relations. Greenwood, Oliver, Suddaby, and Sahlin-Andersson (2008) outlined one of the key tenants of institutional theory is that organizations are influenced by their institutional context. From this central premise, scholars have examined concepts such as status and reputation (Ertug \& Castellucci, 2013; Patterson, Cavazos, \& Washington, 2014), network ties (Battilana \& Casciaro, 2012), trust (Bachmann \& Inkpen, 2011), institutional environments (Suddaby, Elsbach, Greenwood, Meyer \& Zilber, 2010), and social capital (Bartsch, Ebers, \& Maurer, 2013).

Institutional theory and its related concepts have also been examined in various sport settings, representing an opportunity for researchers to contribute to existing research (Washington \& Patterson, 2011). O'Brien and Slack (2003) noted the organizational field is an appropriate level of analysis of organizational changes in sport due to the difference between sport organizations and for-profit firms in relation to a sport organization's association with its organizational field and its subjection to pressures from key suppliers, consumers, competitors, and regulatory agencies. One such field is intercollegiate athletics (Washington, 2004; Washington \& Patterson, 2011; Washington \& Ventresca, 2008) with previous research examining concepts and issues related to isomorphism (Cunningham \& Ashley, 2001; Cunningham, Sagas, \& Ashley, 2001), logics (Southall, Nagel, Amis \& Southall, 2008; Southall \& Nagel, 2008), legitimacy (Washington, 2004-05), and status (Washington, 1999, 2004).

Despite the recent popularity of these institutional theory concepts in the sport management literature, one overlooked aspect of institutional theory is an organization's social identities (Washington, 2004-05). According to social identity theory, a firm creates its own identity based on its particular ideals and characteristics (Albert \& Whetten, 1985; Ashforth \& Mael, 1989; Dutton, Dukerich, \& Harquail, 1994; Elsbach \& Kramer, 1996). This established identity allows organizations to associate with other firms based on categories derived from prototypical and societal ideals (Tajfel \& Turner, 1985; Turner, 1985). Once a firm determines its social identity, it can interact with others they recognize as similar (the in-group) while distancing themselves from rival firms (the out-group) (Mael \& Ashforth, 1992).

Within the sport management literature, researchers have primarily explored social identity from an individual perspective compared with examining organizations (Fink, Parker, Brett, \& Higgins, 2009; Heere \& James, 2007). However, some scholars applied social identity theory in relation to a change in group affiliation. As an example, Washington (2004, 2004-05) studied the movement of universities from the National Association of Intercollegiate Athletics (NAIA) to the National Collegiate Athletic Association (NCAA) to determine if particular social identities influenced NAIA members to leave the association to join the NCAA. To analyze movement, he adopted the framework provided by Rao, Monin, and Durand (2003), whom analyzed organizations moving from one stock exchange (e.g., the NASDAQ) to another stock exchange (e.g., the New York Stock Exchange). Rao et al. (2003) found a firm's defection from the NASDAQ constituted an identity-discrepant cue for fellow NASDAQ organizations to consider a move of their own. Those deciding 
to move engaged in a social mobility strategy, a form of organizational change that utilizes environmental elements to influence a change in an organization's identity (Rao, Davis, \& Ward, 2000).

In terms of college movement, Washington (2004, 2004-05) found many NAIA member schools departed the organization for the NCAA following the departures of other NAIA members. Most schools left the NAIA for the NCAA due to each organization's view within the organizational field. Specifically, university decision makers hold the NCAA in higher prestige due to the firm's association with large universities while the NAIA is considered a lower-order organization due to its affiliation with smaller schools (Land, 1977; Smith, 2011; Washington, 1999, 2004, 2004-05; Weaver, 2010). Thus, NAIA members were presented with the choice to join the more prestigious organization (i.e., the NCAA) or maintain membership with the less acknowledged firm (i.e., the NAIA) (Washington, 2004-05). Furthermore, past researchers have confirmed certain characteristics can bolster the influence prior departures have on schools considering a change in athletic affiliation such as geographic location and historically black college and university (HBCU) designation (Smith, Williams, Soebbing, \& Washington, 2013; Washington, 2004, 2004-05).

Universities conducting athletic affiliation reclassification do not move in a general pattern (i.e., NAIA to NCAA) but instead plan strategically and assess which NCAA division is better suited for their institution. In other words, it is possible that officials analyze the probability of strategic movement based on the social identities of the institution. The purpose of this study was to determine if a school's social identities influence the likelihood of movement from the NAIA to Division II or Division III. The present research reviews the concepts of social identity theory, social mobility, and mimetic pressure along with their application to college movement. Then, the study estimated a logistic regression model incorporating university identities such as HBCU designation, women's college designation, and geographic location to determine if certain identities can determine the strategic movement of schools from the NAIA to Division II or Division III.

\section{Theoretical Framework and Literature Review}

Ashforth and Mael (1989) described social identification as the perception of belongingness to a particular group or human aggregate based on certain characteristics. Essentially, an individual can discover a sense of belongingness to a group or association by recognizing organizations with similar characteristics (Mael \& Ashforth, 1992). Through group association, individuals and organizations identify and interact with fellow members within the in-group and distance themselves from those within the out-group. This methodology leads to the development of positive and negative stereotyping between the in-group(s) and the out-group(s) respectively (Washington, 2004-05). The relationship between in-groups and out-groups is bound to cause conflict, which can result in the possible defection of members (Halevy, Weisel, \& Bornstein, 2012). As an example, an in-group member could view member departures to a rival firm as an issue with the specific association and desire a defection of his/her own. According to Washington (2004-05), "the 
discrepancy is derived from the fact that the focal organization's identity might be linked to the behavior of a peer (defection from an association) that is different from the focal organization's behavior" (p. 34).

Pratt and Foreman (2000) argued conflict emerges within organizations when firms possessing multiple identities concentrate on the management of only one particular identity. In contrast, organizations with multiple dynamic characteristics can function harmoniously when firms belong to either a lower-order or higher-order category that is institutionalized in a formal social system and with cross-cutting demographic categories (Ashforth, 2001; Turner, 1985). When organizations engage in identity conflict, Rao et al. (2003) identified three specific strategies firms can implement: social creativity, social change, and social mobility. Social mobility describes an actor's ability to exit the in-group and join an out-group (Rao et al., 2000), and is preferred over social creativity and social change when a change in group membership is possible (Ellemers, Spears, \& Doosje, 1997; Jackson, Sullivan, Harnish, \& Hodge, 1996).

Social mobility occurs in two different forms. First, organizations requesting membership in a particular institution will mold their own personal characteristics to match the current members of that institution and disassociate with other organizations that possess their former characteristics (Taylor \& McKirman, 1984). Firms use this particular strategy along linguistic, cultural, and other modifiable dimensions (Hogg \& Terry, 2000). Second, organizations can adopt the characteristics of the institution's members while maintaining their prior associations. Groups formed on the basis of sex, race, and other invariant characteristics often engage in this type of social mobility (Taylor \& McKirman, 1984).

Group members can, therefore, use defections as an identity-discrepant cue to determine if a positive social identity can be maintained. These cues can act as an isomorphic pressure, forcing firms to implement a social mobility strategy based on the actions of both their peer and rival organizations as well as adopting rationalized ideals of an organizational field (Rao et al., 2003). Rationalized myths are commonly accepted practices within the organizational field and society that a firm adopts in an attempt to bolster its legitimacy and its survival prospects (Meyer \& Rowan, 1977). According to DiMaggio and Powell (1983), three specific pressures (i.e., coercive, mimetic, or normative) emerge and encourage firms to alter its organization to remain more homogeneous with other respected institutional structures. Coercive pressures stem from political influences and other power relationships (Boxenbaum \& Jonsson, 2008). Mimetic pressures arise from uncertainty and lead organizations to imitate their perceived successful peers (DiMaggio \& Powell, 1983). Finally, normative pressures center on what an organization deems as a proper course of action or moral duty to act (Suchman, 1995). As rationalized myths develop, the potential for institutional isomorphism increases as firms conform and become deeply institutionalized (Boxenbaum \& Jonsson, 2008).

Although firms can implement a social mobility strategy under any of the three pressures, past research tends to identify mimetic pressure as a catalyst for most movement. Both Strang and Soule (1998) and Tolbert and Zucker (1983) noted the strong connotation between cognitive legitimacy and mimetic isomorphism. Specifically, both studies argued when more organizations adopt a specific practice, firms face higher pressure to copy their competition, leading to the establishment of 
the innovation's legitimacy in the organizational field. Further, when this process occurs, decision makers generally model their firm similar to early adopters, which may alter the identity of the organization. Thus, as time progresses and innovations spread through an organizational field, they evolve into rationalized myths and become acceptable norms (Schneiberg \& Lounsbury, 2008). Within intercollegiate sports, both the NCAA and the NAIA developed innovations (e.g., creating the first college-only basketball tournament; accepting HBCUs as full members) to attract new members and maintain their respective standings. However, this competition forced both organizations to alter their respective institutional strategy, impacting their respective membership counts and their organizational field for years to come.

\section{History of NAIA and NCAA Conflict}

The organizational field of intercollegiate athletics rationalizes the NCAA is the most prestigious college sports association in the United States due to its affiliation with prominent universities (Getz \& Siegfried, 2010; Smith et al., 2013). However, the NCAA is not the only firm providing intercollegiate athletic governance to member schools. The NAIA is an intercollegiate athletic association that provides college sport governance to small colleges and universities (Wilson, 2005). The two associations competed for new members since the NAIA's inception in 1937 (Stooksbury, 2010). The NAIA differentiated itself from the NCAA by developing relationships with colleges traditionally viewed as nonprototypical NCAA members such as teaching colleges, liberal arts colleges, and HBCUs (Washington, 2004). By providing these schools with college sport governance, the NAIA created a substantial niche in the intercollegiate athletic organizational field (Smith, 1988). Furthermore, the NAIA provided schools with the power to self-govern as opposed to the NCAA's centralized management approach (Land, 1977). The early success of the organization in the 1940s allowed the NAIA to establish its legitimacy within intercollegiate athletics and act as a viable competitor for membership to the NCAA during the 1950s and 1960s (Wilson, 2005).

As the NAIA attracted new members, the NCAA also implemented practices to encourage schools to join their organization. For example, in 1957, NCAA officials agreed to reorganize its firm into a two division structure (e.g., University and College), providing athletic governance to schools the NCAA previously ignored (Falla, 1981). By creating the College Division, the NCAA made an attempt to solicit smaller colleges in the NAIA to join the NCAA, specifically HBCUs (Katz, 1990; Katz \& McLendon, 1988). Although the divisional structure was successful, the NAIA and the NCAA still maintained relatively similar membership counts (Wilson, 2005). By 1966, NAIA membership grew to 517 members while the more established NCAA, in comparison, possessed 536 members (Washington, 2004-05).

The organizations would continue to engage in a membership stalemate until 1973 when the NCAA began a second reorganizational effort and created the current three division structure (e.g., Division I, Division II, and Division III) (Falla, 1981; Wilson, 2005). The NCAA encouraged schools to join through guaranteed financial commitments to both Division II and Division III ("Football Rights Fees Announced", 1976; Washington, 2004-05). The NAIA could not match the NCAA's financial commitments, and thus, many NAIA members left the organization and 
joined the NCAA (Smith, 1988; Washington, 2004). Between 1973 and 2013, the NAIA lost over 250 members (Washington, 2004; Williams, 2014; Wilson, 2005).

\section{College Movement}

Within the college movement literature, both social mobility and, to a lesser extent, mimetic pressures were studied to predict the likelihood movement of schools from the NAIA to the NCAA. Washington (2004) explored the evolution of the NCAA in response to the organizational field changes caused by the NAIA through two specific time periods (e.g., 1906-1952 and 1952-2004). Washington (2004) hypothesized the NCAA focused on specific schools for membership before 1952, allowing the NAIA to thrive. According to the results, liberal arts schools, HBCUs, and teachers' colleges were less likely to make a transition to the NCAA before 1952 because of the NCAA's decision to rank these institutions as lower-order organizations (Washington, 2004). However, after 1952 and the creation of the College Division, institutions with these designations transitioned into the NCAA more frequently.

In a later study, Washington (2004-05) reviewed the status of 500 institutions whom were members of the NAIA from 1973 to 1999,255 of which chose to leave the NAIA for the NCAA, to determine if a school's social identities influence college movement. Washington (2004-05) incorporated Rao et al.'s model (2000), which noted firms moving from the NASDAQ to the NYSE viewed defections as an identity-discrepant cue for remaining organizations within a particular in-group to consider a similar move to the NYSE. According to Washington (2004-05), firms can possess multiple social identities that have the ability to be simultaneously salient. Specifically, HBCUs and NAIA athletic conference affiliated schools were more likely to follow NAIA defectors sharing those characteristics and join the NCAA (Washington, 2004-05).

Smith et al. (2013) expanded on the Washington (2004-05) study by addressing two of its limitations. First, Smith et al. (2013) analyzed all NAIA members from 1968 to 2011, which included all members joining the NAIA after Washington's (2004-05) 1973 cutoff date. Second, Smith et al. (2013) concentrated on the geographic location of each school instead of their NAIA conference affiliation. According to Smith et al. (2013), conference affiliation does not possess certain geographical factors that can influence a firm to engage in a social mobility strategy. Smith et al. (2013) also incorporated other social identities not found in previous college movement studies such as women's institution designation, religious affiliation, and the Carnegie Foundation size classification (i.e., very small, small, medium, or large college). The results revealed schools located in the New England and Rocky Mountain regions would be more likely to change affiliations when similar institutions within close proximity decide to move to the NCAA. On the other hand, institutions in the Southeast and Mideast regions would be less likely to change affiliations. Finally, religious affiliated universities, women's institutions, and small or medium sized schools would also be more likely to move from the NAIA to the NCAA.

Although prior studies acknowledge certain social characteristics can predict the likelihood of a school transitioning from the NAIA to the NCAA (Smith et al., 2013; Washington, 2004-05), these studies only considered movement from a 
general standpoint as opposed to the specific division a university chooses to affiliate. University officials need to consider the differences in NCAA divisions such as the number of sports to offer, the total population of the school, and the issuance of athletic financial aid instead of only focusing on the NCAA's branding and outreach opportunities (Dwyer, Eddy, Havard, \& Braa, 2010; Smith, 2011; Weaver, 2010). Furthermore, schools could be pressured to transition between athletic associations before they are ready due to their peers' actions, especially ones that share similar social identities. Thus, the present research addressed the question: Do particular social identities predict the likelihood that NAIA schools will transition from the NAIA to the NCAA Division II or from the NAIA to NCAA Division III?

\section{Methodology}

To investigate the effect social identities have on the likelihood of college movement, the current study examined the initial movement of schools from the NAIA to either NCAA Division II or Division III from 1973 to 2012, which encompasses the creation of both Divisions II and III (Falla, 1981). If a school decides to reclassify into another division within the NCAA after its initial movement, return to the NAIA or join another athletic association, or drop its athletic program altogether, the school will be removed from the sample. Smith, Soebbing, and Washington (2015) noted schools associated with the NAIA shared many similarities with schools aligned with Division II and III but not Division I. Furthermore, Division I membership requirements (e.g., sponsor at least seven sports for men and women, provide minimum financial aid awards to student-athletes, meet minimum football attendance requirements, etc., "Divisional Differences and the History", n.d.) have discouraged NAIA defectors from joining Division I immediately. During the sample period, only 36 schools joined Division I from the NAIA.

The annual membership records for the sample years were obtained directly from the NAIA. ${ }^{1}$ University identities such as location, public/private distinction, HBCU designation, women's college designation, religious affiliation, and sport offerings were collected from the various university websites and other university publications (e.g., yearbooks, newspapers, annals, etc.) as well as the IPEDS database. This database provides data on U.S. postsecondary education to describe and determine trends in the number of students enrolled, number of faculty and staff employed, number of degrees earned, and the total amount of dollars expended ("About IPEDS", n.d.). Schools are required to complete an annual IPEDS survey if they participate in or are applicants for any federal student financial aid program such as Pell Grants and federal student loans. The IPEDS database was used in studies reviewing college athletics and higher education phenomena (e.g., Backes, 2012; Laband \& Lentz, 2004).

The unit of observation is a university-year in accordance with the IPEDS database. The database was analyzed for NAIA member schools based upon the NAIA membership listing. Any institution that merged with another school, changed its name, or closed was identified to ensure no double counting occurred within the data set. Furthermore, the sample does not include any international universities or any U.S. institutions not found in the IPEDS database. Colleges and universities that were members of the NAIA during the sample time period are included in 
the data set one year after departing the NAIA for Division II or Division III. This inclusion allows for the simulation of movement by one institution. After one year in the NCAA, the observed university is removed from the sample. The collection of data and empirical strategy for this study was consistent with methods used by Smith et al. (2013) and Washington (2004, 2004-05). The data set includes 22,367 university-year observations.

\section{Dependent Variable}

A university's movement to either Division II or Division III (Mvmt) is observed through the use of $1 / 0$ dichotomous variable. The value of one indicates an observed university left the NAIA in the current year and transitioned into either Division II or Division III, while zero signifies the university stayed in the NAIA. During the time period analyzed, 264 universities transitioned from the NAIA to Division II and 233 schools moved to Division III.

\section{Independent Variables}

If a university decides to change its affiliation with one particular group, this may influence other universities to consider their own relationship within the association and possibly defect to the out-group as well. The present research incorporated identities used in Smith et al. (2013) and Washington's (2004, 2004-05) research along with some additional identities. The present research also used the same logistic regression estimation strategy found in prior studies (e.g., Smith et al., 2013; Washington, 2004-05) which involved an indicator variable equal to 1 if an observed university possesses an analyzed identity, a count variable indicating the number of universities with the analyzed identity that moved in a particular time period (e.g., current year, previous year, two years prior), and a variable interacting the indicator variable and the count variable. A positive and significant parameter on the interaction variable indicates a university possessing the observed identity is more likely to move to either Division II or Division III as other schools possessing the observed identity move.

The first identity analyzed is the geographic location of the university. Washington (2004-05) considered a school's conference affiliation within the NAIA as a definition of its geography. Smith et al. (2013) altered this approach by utilizing the eight IPEDS definitions for geographical regions. The present research used these same regional classifications: New England, Mid-East, Great Lakes, Plains, Southeast, Southwest, Rocky Mountain, and Far West.

The second social identity grouping is religious affiliation. Steensland, Park, Regnerus, Robinson, Wilcox, and Woodberry (2000) cautioned researchers on how to categorize and study religious groupings. Specifically, they argued religious denominations should be grouped according to their affiliation within six nominal categories as opposed to each denomination's specific ideology to avoid any potential historical, terminological, and taxonomical inaccuracies that may occur when focusing on concrete religious traditions. These categories are Mainline Protestant, Evangelical Protestant, Black Protestant, Roman Catholic, Judaism, and Other (e.g., Mormon, Jehovah's Witness, Muslim, Hindu, and Unitarian). Both Smith et al. (2013) and Washington (2004-05) incorporated religious affiliation within their 
respective studies but reported mixed results. Specifically, Washington (2004-05) noted schools with a religious affiliation were less vulnerable to the pressure to change athletic affiliation after previous institutions defected from the NAIA to the NCAA. On the other hand, Smith et al. (2013) noted religious affiliation had no significant impact on the likelihood of movement. However, neither study used Steensland et al.'s (2000) classification system.

The third and fourth identities relate to the HBCU or women's only school designation. Both Smith et al. (2013) and Washington (2004, 2004-05) included HBCUs while Smith et al. (2013) introduced women's only schools. These designations are important since both the NAIA and the NCAA previously focused on the admission of these schools at specific points in time [e.g., HBCUs in the 1950s; women's colleges in the 1970s (Falla, 1981; Wilson, 2005)]. The fifth identity grouping involves schools classified as private. Prior studies on college movement did not test if the private school designation influenced the likelihood of reclassification. Instead, Smith et al. (2013) created a count variable for the number of public schools to control for the movement of schools that were not classified as an HBCU, women's college, or affiliated with a religion. Smith et al. (2013) used this variable because schools designated as an HBCU, women's college, or affiliated with a religion are private institutions. However, some institutions are classified as private schools without another distinction.

Size classification based upon the classifications designed by the Carnegie Foundation is the sixth social identity grouping. According to the foundation, the Carnegie Classification system is widely used by higher education scholars to analyze and control for institutional differences ("About Carnegie Classification", n.d.). To reduce the number of classifications from 18, Smith et al. (2013) aggregated the Carnegie Classification system into four specific categories: (1) very small or small; (2) medium; (3) large or very large; and (4) not classified by Carnegie. The present research used these four Carnegie size classifications.

The final social identity grouping was a university's sponsorship of revenue generating sports. Traditionally, scholars argued only two revenue generating sports exist within intercollegiate athletics: (1) football and (2) men's basketball (Fulks, 2014; Kahn, 2007). With the inclusion of women's only colleges, the present research also included women's basketball as an identity as these schools do not sponsor men's sport.

\section{Control Variables}

To control for time-based effects, the current study used a control variable to represent each year of the sample setting (TREND). The year 1973 will take a value of one. TREND will continue to increase until it reaches the year 2012, taking a value of 40. In addition, a count variable sums all schools moving from the NAIA to either Division II or III in the prior year and two years before the current year. Finally, the present research controlled for the tenures of each of the NAIA leaders. During the sample period, six individuals served as the NAIA Executive Secretary/ CEO. Al Duer was Executive Secretary from 1949 to 1975. Duer retired in 1975 and was replaced by Harry Fritz. Fritz would stay on as leader until 1986 when he was removed from office. Jefferson Farris was named NAIA Executive Secretary/ CEO in 1986 and served until 1990. After Farris stepped down, James Chasteen 
took over as CEO in 1991. In 1996, Chasteen was removed from office and Steve Baker was appointed CEO. Baker stepped down in 2006, and Jim Carr took over as CEO and continues to serve as of 2014. An indicator variable for each leader is included in the model taking the value of one if the university-year observation is within the leader's tenure and 0 for all other years.

\section{Model and Estimation Issues}

Since the dependent variable in the present research was a dichotomous $1 / 0$ variable, discrete estimation techniques such as logit and probit should be used (Maddala, 1983). The present research estimated a logistic regression model similar to both Washington (2004-05) and Smith et al. (2013). Equation 1 presents the broad model:

$$
\begin{gathered}
\text { MVMT }_{\mathrm{ij}}=\mathrm{f}\left(\mathrm{GEO}_{\mathrm{ij}}, \text { REL }_{\mathrm{ij}}, \text { BCU }_{\mathrm{ij}}, \text { WOMEN }_{\mathrm{ij}}, \text { PRIVATE }_{\mathrm{ij}}, \text { SIZE }_{\mathrm{ij}}, \text { SPORTS }_{\mathrm{ij}}, \text { TREND }_{\mathrm{ij}},\right. \\
\text { DUER } \left._{\mathrm{ij}}, \text { FRITZ }_{\mathrm{ij}}, \text { FARRIS }_{\mathrm{ij}}, \text { CHASTEEN }_{\mathrm{ij}}, \text { TOTAL }_{\mathrm{i}(\mathrm{j}-1)} \text { TOTAL }_{\mathrm{i}(\mathrm{j}-2)}, \epsilon_{\mathrm{ij}}\right)
\end{gathered}
$$

where $i$ indexes schools, $j$ indexes years, and $\mathrm{E}$ is the equation error term. Different from previous research examining college movement, two different models were estimated to differentiate between schools making an initial movement to Division II or Division III.

Two potential estimation issues existed that could affect the accuracy of the results. The first was multicollinearity, which occurs when two independent variables are very highly correlated (Abraham \& Ledolter, 2006; Schroeder, Sjoquist, $\&$ Stephan, 1986). With the inclusion of interaction terms, there is a potential concern regarding multicollinearity. However, previous research notes that a strategy to avoid the multicollinearity problem is to increase the sample size to bring out the differences in variables and reduce the correlation (Mason \& Perreault, 1991). Because of the large sample size used in this analysis, multicollinearity is not expected to be a problem with the exception in the interaction variables. The second estimation issue dealt with the standard errors of the data. Because the data set for the current study was comprised of many universities over a period of time, some unobserved heterogeneity that is similar within each university's observations was present. As a result, the standard errors of the logistic regression model are clustered by university and year.

\section{Results}

Table 1 displays the summary statistics for the various university identities used in the analysis. In the sample, $1.9 \%$ of the university-year observations occur when the university initially joins Division II and $1.0 \%$ of observations join Division III. Private schools comprise over $76 \%$ of the sample observations while women's only institutions and HBCUs comprise approximately $3 \%$ and $6.5 \%$ respectively. Most observations occurred under Fritz' tenure as leader of the NAIA (32\%), followed by Baker (17\%), and Farris (14\%).

Table 2 provides additional observation tabulations. Of the eight regions identified, the Rocky Mountain region has the lowest amount of observations 


\section{Table 1 Summary Statistics}

\begin{tabular}{lccccc}
\hline Variable & Mean & Std. Dev & Min & Max & Median \\
\hline To Division II & 0.019 & 0.108 & 0 & 1 & 0 \\
To Division III & 0.010 & 0.102 & 0 & 1 & 0 \\
Private & 0.762 & 0.426 & 0 & 1 & 1 \\
Women's & 0.029 & 0.168 & 0 & 1 & 0 \\
BCU & 0.065 & 0.246 & 0 & 1 & 0 \\
Catholic & 0.138 & 0.345 & 0 & 1 & 0 \\
Mainline Protestant & 0.229 & 0.420 & 0 & 1 & 0 \\
Evangelist Protestant & 0.174 & 0.380 & 0 & 1 & 0 \\
Black Protestant & 0.008 & 0.088 & 0 & 1 & 0 \\
Other Christian & 0.002 & 0.040 & 0 & 1 & 0 \\
Other Religious Affiliations & 0.004 & 0.064 & 0 & 1 & 0 \\
Duer & 0.109 & 0.312 & 0 & 1 & 0 \\
Fritz & 0.322 & 0.468 & 0 & 1 & 0 \\
Farris & 0.140 & 0.347 & 0 & 1 & 0 \\
Chasteen & 0.146 & 0.352 & 0 & 1 & 0 \\
Baker & 0.172 & 0.377 & 0 & 1 & 0 \\
Carr & 0.110 & 0.313 & 0 & 1 & 0 \\
\hline
\end{tabular}

$n=22,367$

(3.09\% of the total sample) while the Southeast region has the largest amount (29.03\%). Examining the religious affiliations, 55.5\% of observations are affiliated with a religious denomination. Specifically, $22.87 \%$ of the observations align with a Mainline Protestant denomination, $17.45 \%$ of the sample affiliate with an Evangelist Protestant denomination, and $13.84 \%$ of observations serve the Roman Catholic faith. In terms of size, $69.1 \%$ of the observations are small or very small schools, $20 \%$ of observations are medium sized schools, $3.10 \%$ of observations are large or very large institutions, and $7.92 \%$ of observations are not classified by the Carnegie Foundation. Finally, 70.62\% university-year observations sponsor men's basketball, $64.06 \%$ sponsored women's basketball, and only $27.36 \%$ of the observations sponsored a football team.

Tables 3 and 4 present the results from the logistic regression model predicting the likelihood the focal university will move from the NAIA to Division II and Division III respectively. ${ }^{2}$ The present study analyzed three variations of the logistic regression model. Model One examines only the control variables used in this study. Model Two reviews the control and independent variables but no interaction variables. Model Three includes all variables used in the study specifically the interaction variables. The present study discusses the results found from the full model (Model Three). 
Table 2 University Tabulations

\begin{tabular}{|c|c|c|c|}
\hline Identity & Variable Names & $\begin{array}{c}\text { Total } \\
\text { Number }\end{array}$ & $\begin{array}{c}\% \text { of } \\
\text { Sample }\end{array}$ \\
\hline \multirow{8}{*}{$\begin{array}{l}\text { IPEDS Geographic } \\
\text { Regions }\end{array}$} & New England (NE) & 1,008 & 4.51 \\
\hline & Mid-East (ME) & 1,898 & 8.49 \\
\hline & Great Lakes (GL) & 3,826 & 17.11 \\
\hline & Plains (PL) & 3,670 & 16.41 \\
\hline & Southeast (SE) & 6,493 & 29.03 \\
\hline & Southwest (SW) & 2,363 & 10.56 \\
\hline & Rocky Mountain (RM) & 691 & 3.09 \\
\hline & Far West (FW) & 2,418 & 10.81 \\
\hline \multirow[t]{6}{*}{ Religious Affiliations } & Catholic (CATH) & 3,095 & 13.84 \\
\hline & Mainline Protestant (M_PROT) & 5,116 & 22.87 \\
\hline & Evangelist Protestant (E_PROT) & 3,902 & 17.45 \\
\hline & Black Protestant (BL_PROT) & 175 & 0.78 \\
\hline & Other Christian (OTH_CHR) & 36 & 0.16 \\
\hline & $\begin{array}{l}\text { Other Religious Affiliations } \\
\text { (OTH_REL) }\end{array}$ & 92 & 0.41 \\
\hline \multirow[t]{4}{*}{ Size } & $\begin{array}{l}\text { Not Classified by Carnegie } \\
\text { (SIZEC1) }\end{array}$ & 1,772 & 7.92 \\
\hline & Small or Very Small (SIZEC2) & 15,451 & 69.08 \\
\hline & Medium (SIZEC3) & 4,450 & 19.90 \\
\hline & Large or Very Large (SIZEC4) & 694 & 3.10 \\
\hline \multirow[t]{3}{*}{ Sponsored Sports } & Football (FB) & 6,119 & 27.36 \\
\hline & Men’s Basketball (MBB) & 15,795 & 70.62 \\
\hline & Women's Basketball (WBB) & 14,328 & 64.06 \\
\hline
\end{tabular}

According to Table 3, several indicator variables show a decrease in the likelihood of movement from the NAIA to Division II. Specifically, schools located in the Plains and Rocky Mountain regions, classified as a small school by Carnegie, or sponsor women's basketball are less likely to move to Division II. In comparison, schools considered large or very large or sponsor men's basketball are more likely to move to Division II. The remaining identities do not show any effect on the likelihood of movement to Division II.

Table 3 also examines the interaction terms to determine the influence other universities who have moved to Division II and possess an observed identity have on a university's possible transition to Division II that shares the observed identity. 


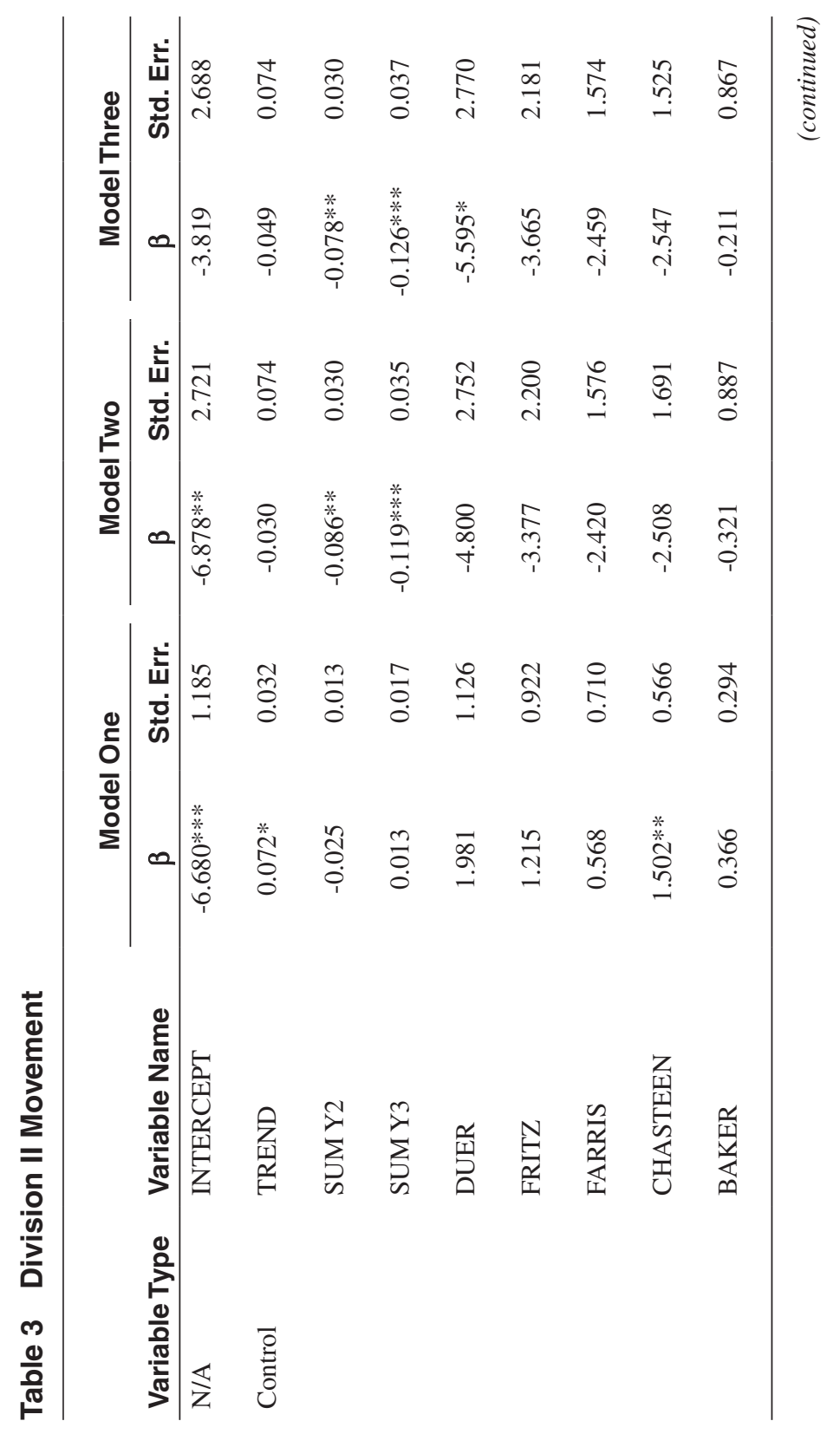




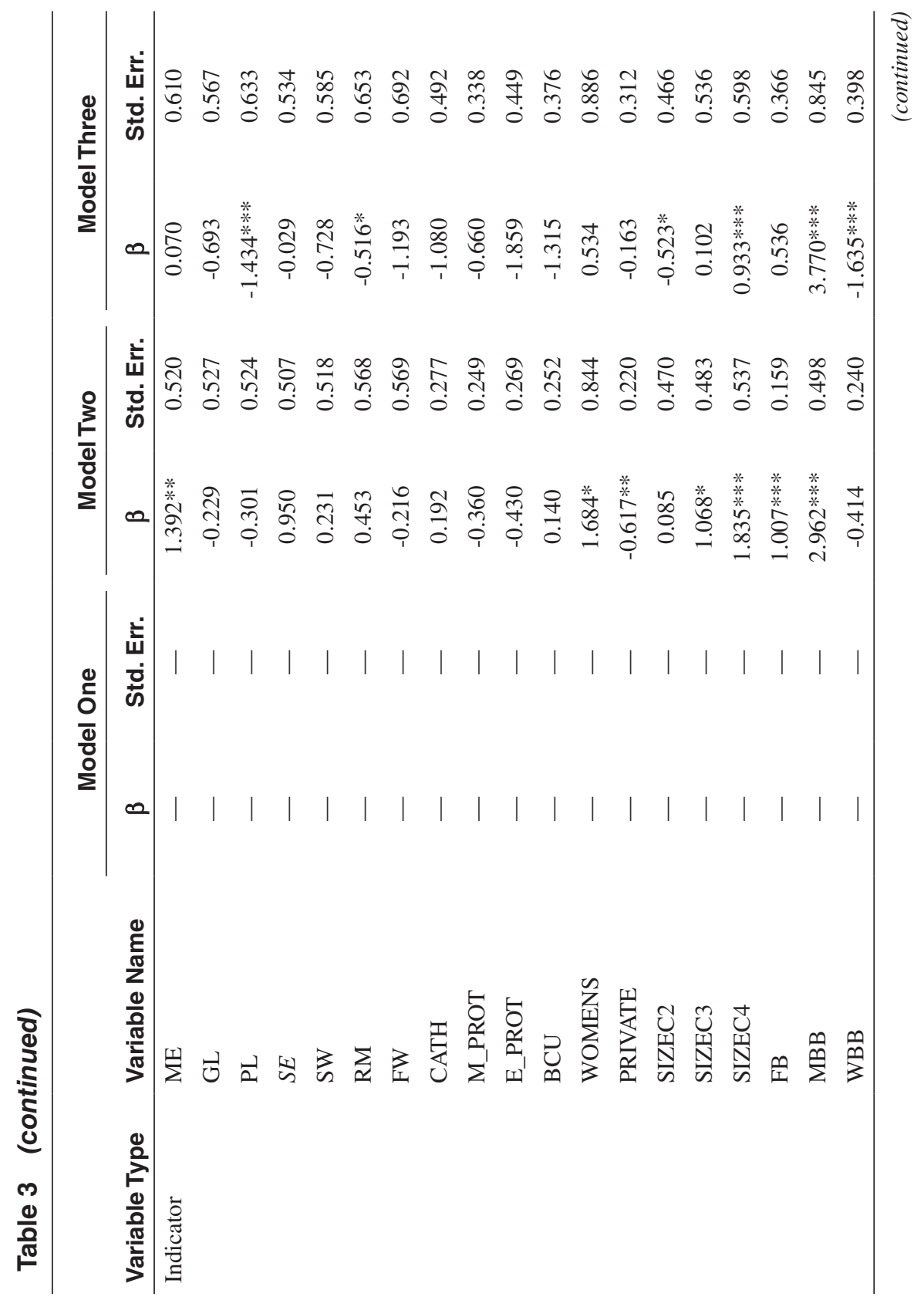




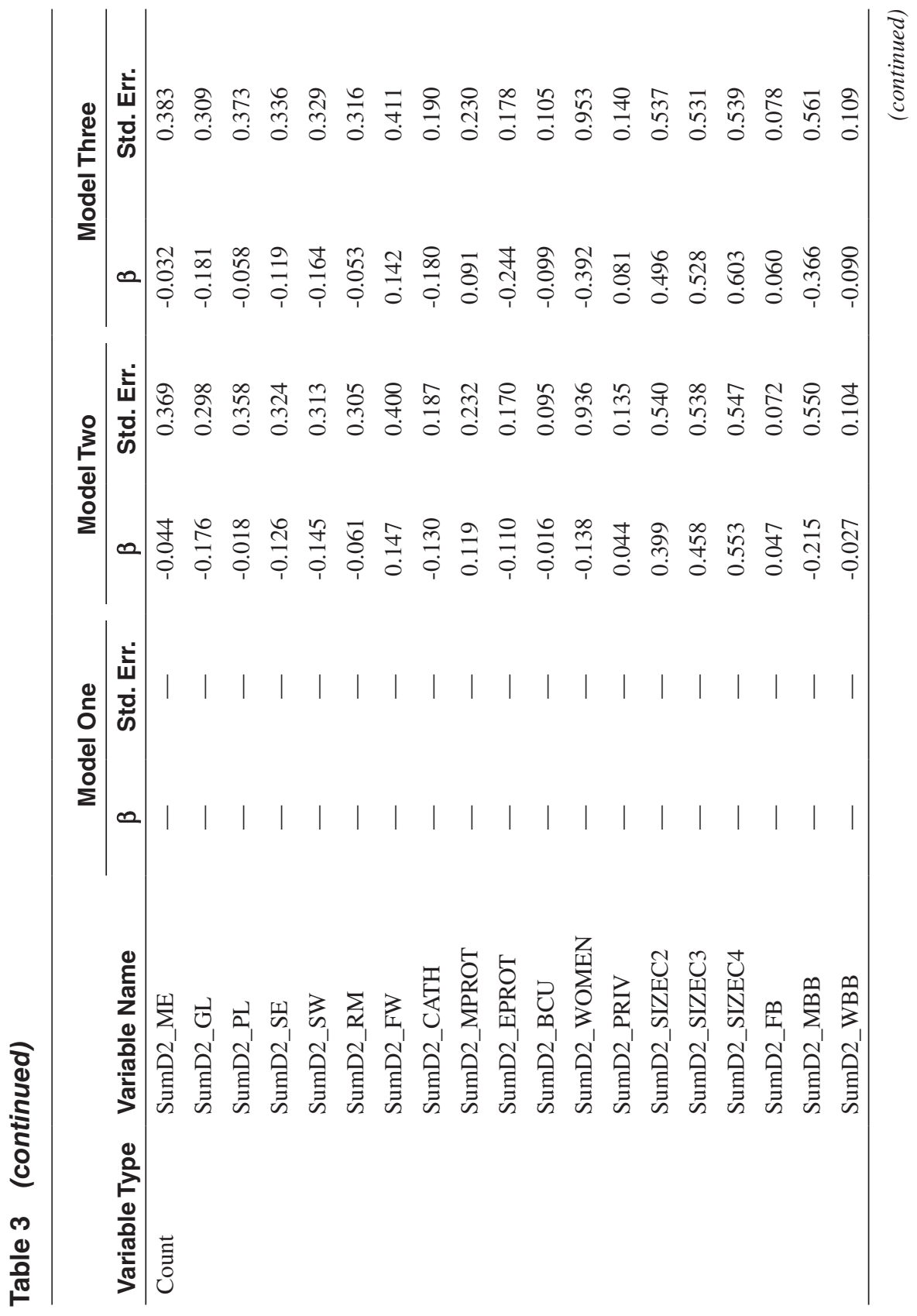




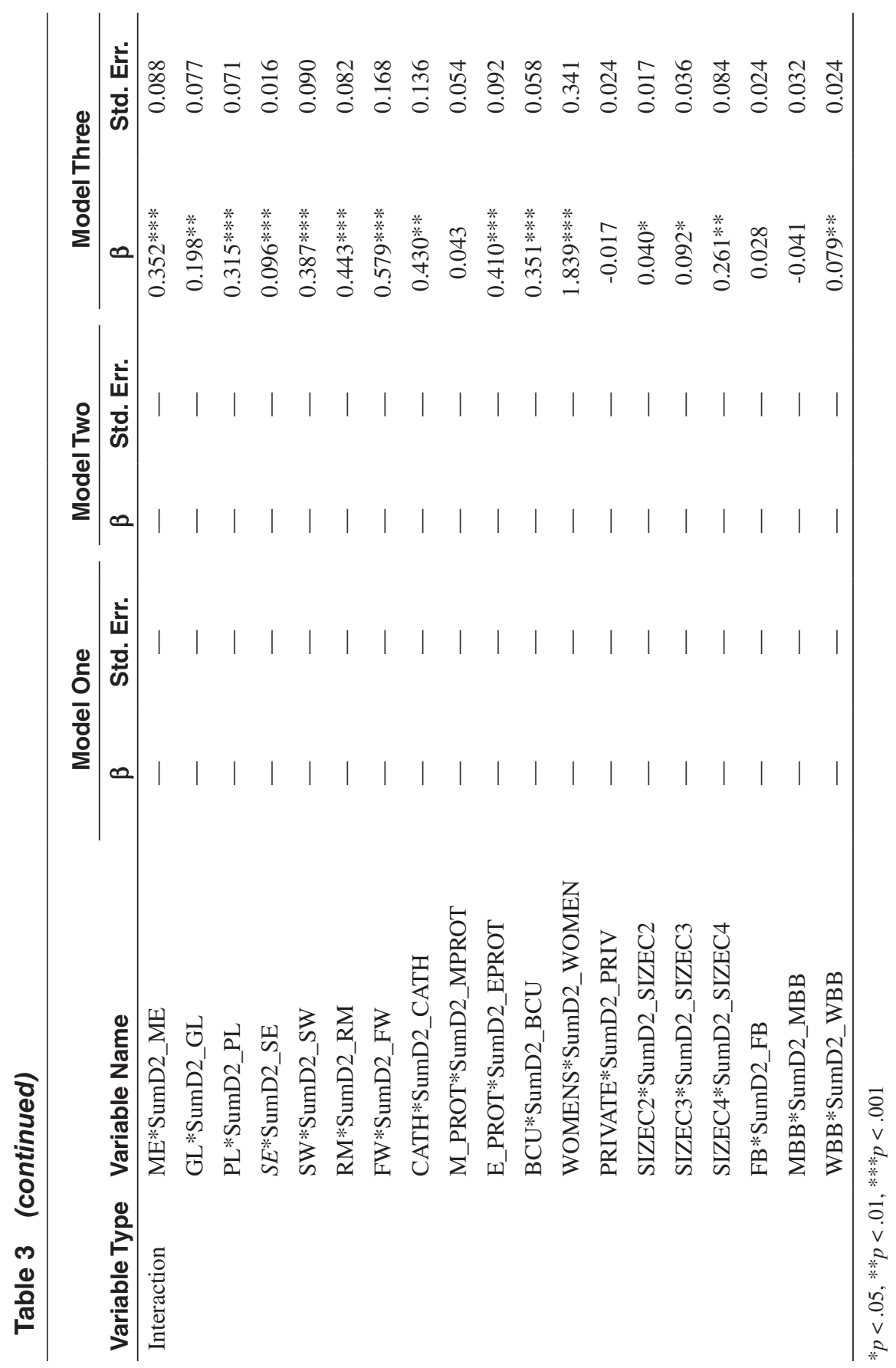




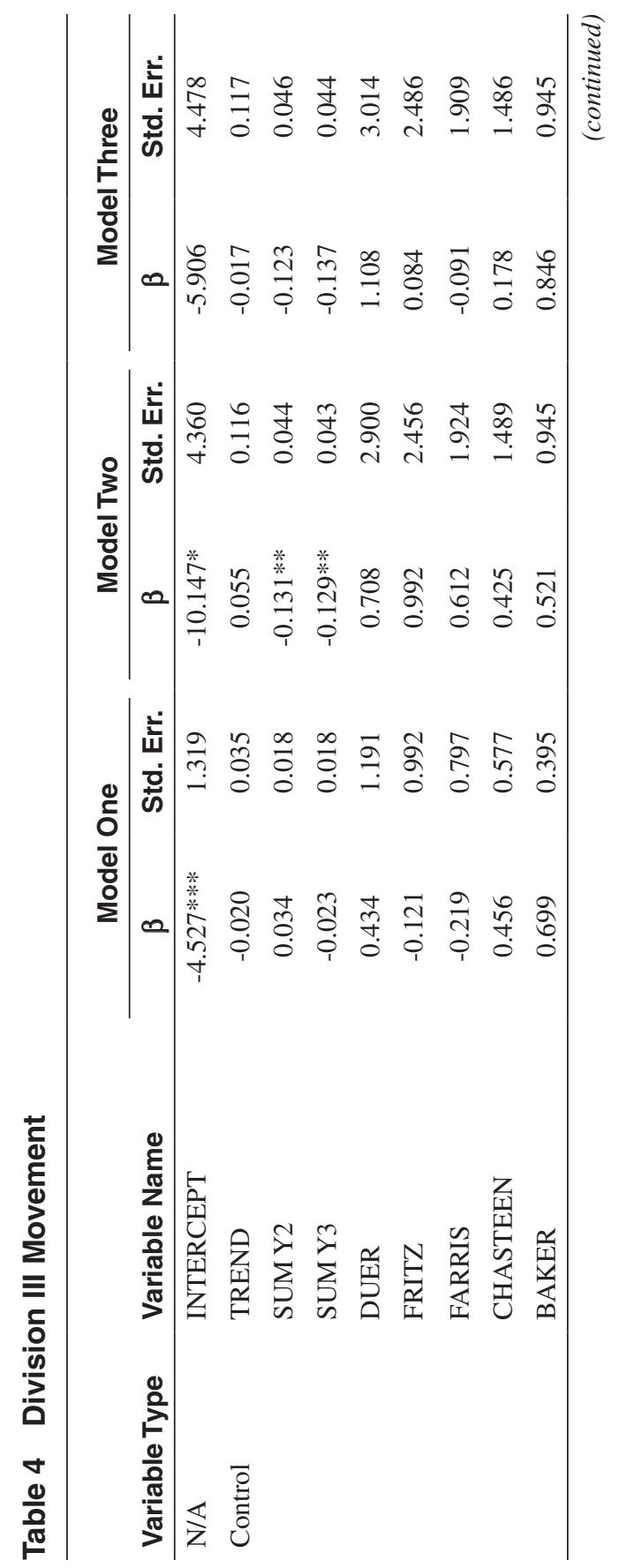




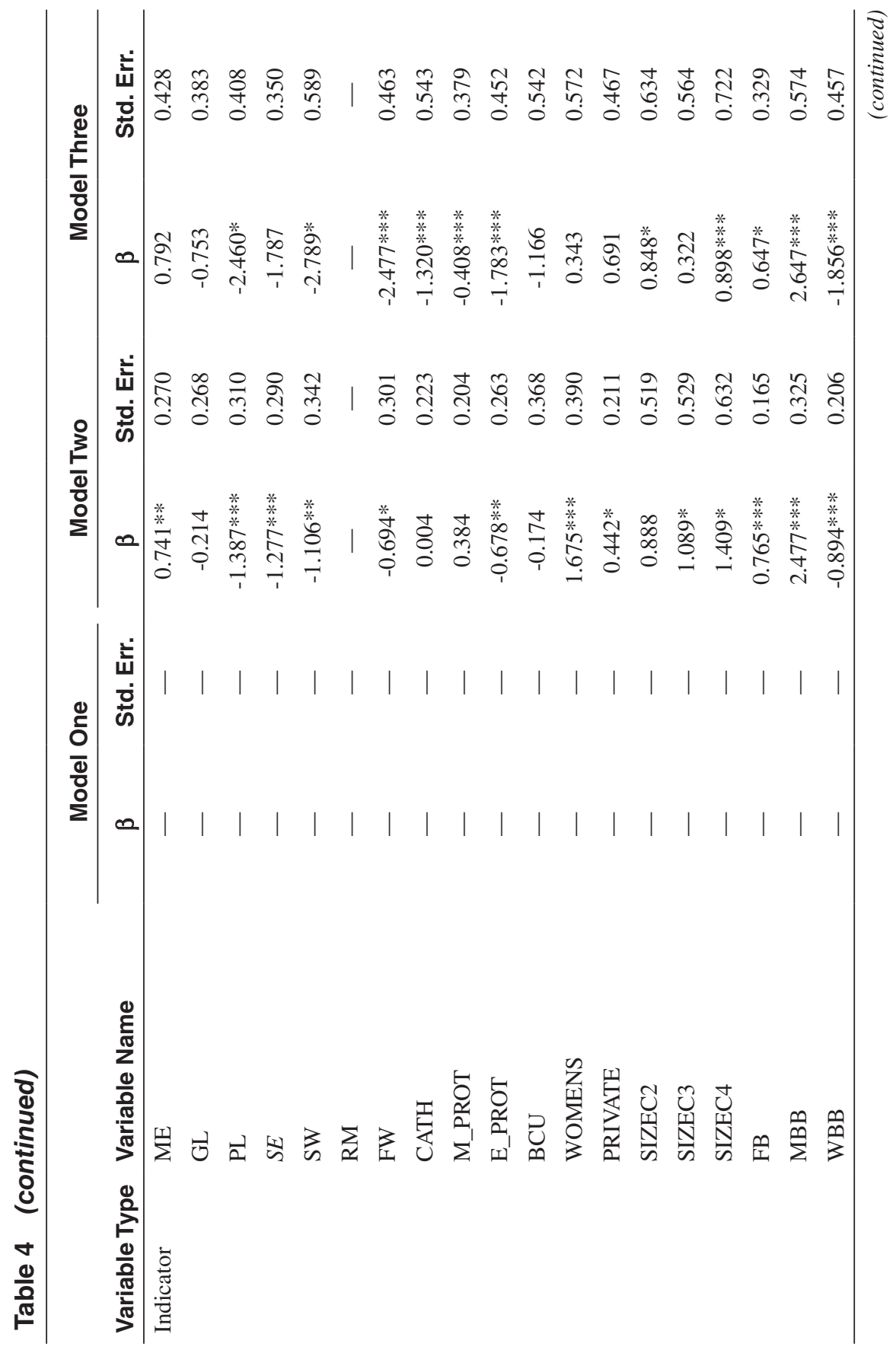




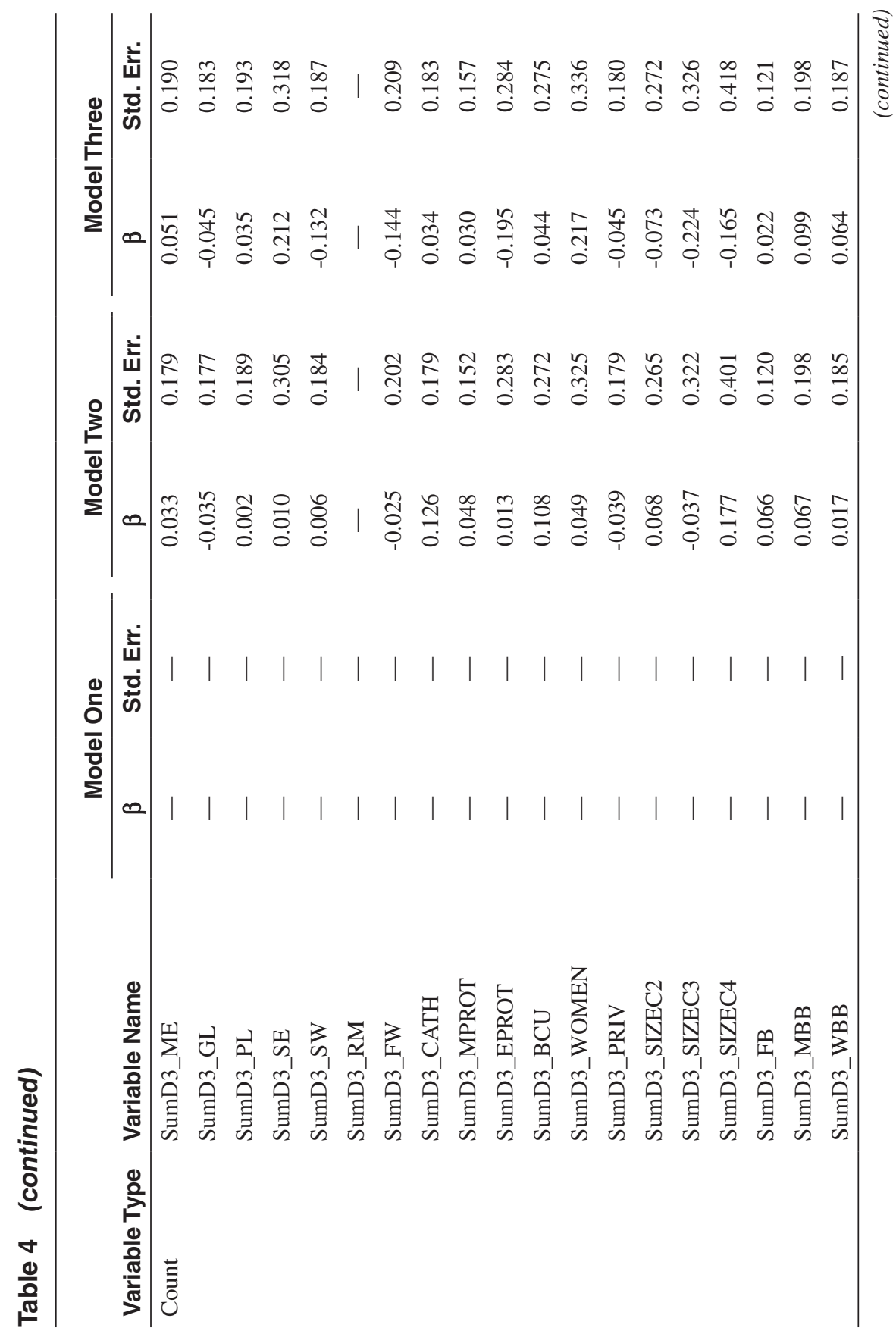




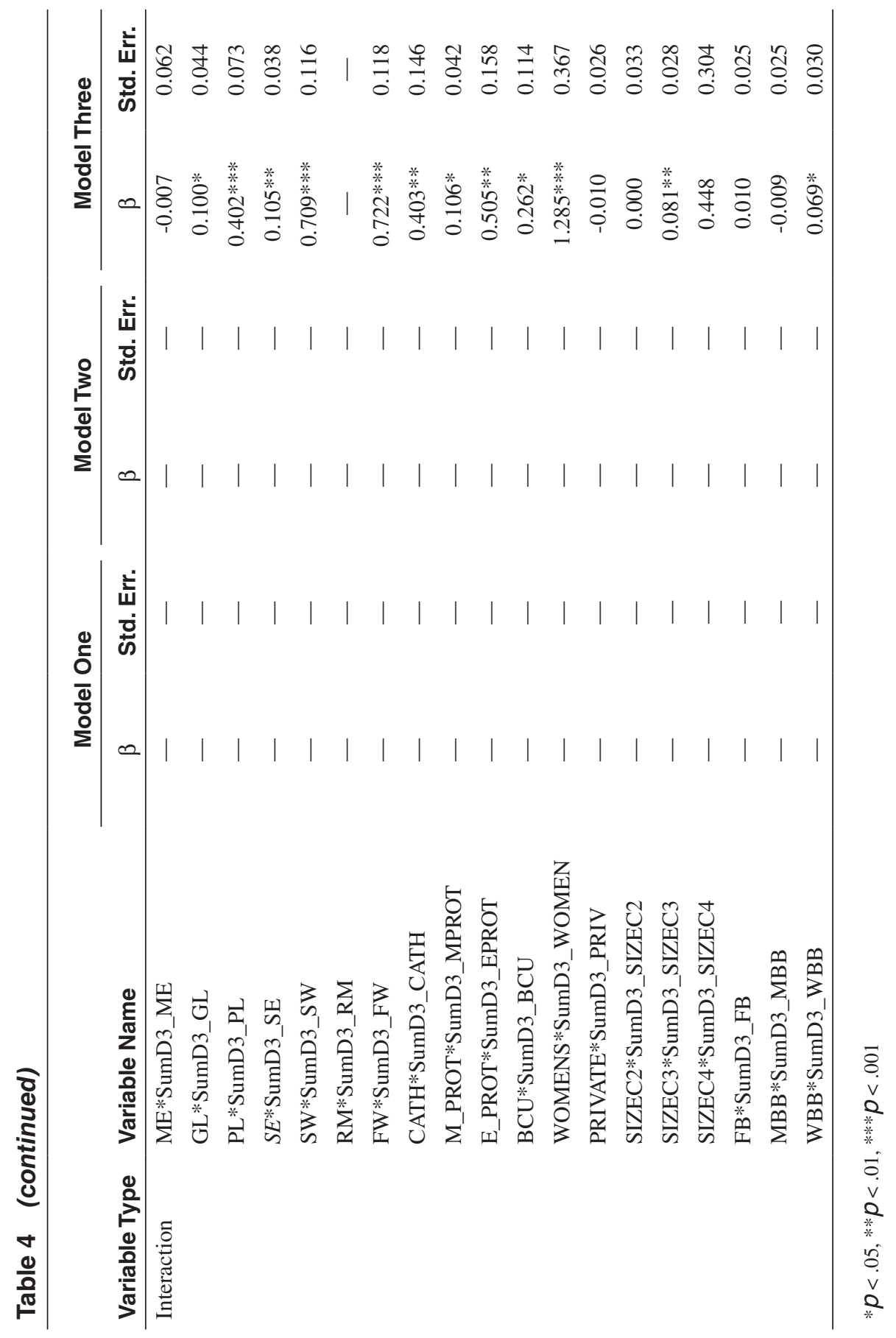


The results show all geographic regions have a positive and significant increase, noting an increased likelihood of movement to Division II. The present study also provides a positive and significant increase in the likelihood of movement for universities affiliated with the Catholic and Evangelist Protestant denominations, HBCUs, women's colleges, all three Carnegie Size Classifications, and universities offering women's basketball. All other identities show no statistical significance in the likelihood of movement from the NAIA to Division II.

For NAIA to Division III movement, Table 4 shows schools found in the Plains, Southwest, and Far West regions, affiliated with Catholic, Mainline Protestant, or Evangelical Protestant denominations, and sponsor women's basketball are less likely to join Division III. However, schools considered small or large or sponsoring football and men's basketball are more likely to move to Division III. All other identities are not statistically significant.

In terms of the interaction variables, Table 4 notes schools located in the Great Lakes, Plains, Southeast, Southwest and Far West Regions are more likely to move from the NAIA to Division III due to an increase in the number of schools moving from each respective region. In addition, all religious denominations, HBCUs, women's colleges, medium sized colleges, and schools sponsoring women's basketball show greater tendencies of movement to Division III. All other interaction variables do not show any statistical significance.

\section{Robustness Checks}

To test for the robustness of the model, the study prepared five different variations of each model used. The first variation predicted the likelihood of a school moving to either Division II or Division II in the current year (Y1) based upon the social identities of other schools moving in the current year. The second estimated a school's potential for movement in Y1 based upon the transition of schools from the prior year (Y2), while the third variation analyzed school movement in relation to colleges relocating two years (Y3) before the current year. The fourth variation projected the likelihood of movement in Y1 by combining past efforts in Y2 and Y3. Finally, the fifth variation, which is reported in Tables 3 and 4, estimated the potential for schools to transition to Division II based upon the movement of other schools in Y1, Y2, and Y3. After calculating the models, the results proved to be consistent throughout with no significant changes (i.e., a negative relationship turning positive; a significant variable becoming nonsignificant). Thus, the study argues the results presented in Tables 3 and 4 are robust.

\section{Discussion}

In Smith et al.'s (2013) research, a university's geographic location was a major contributing factor for schools to depart the NAIA for the NCAA. While Smith et al. (2013) found drastic differences among the eight regions, Table 3 shows movement from the NAIA to Division II is more likely to occur in all regions after other schools from the region depart for Division II while Table 4 notes all regions except the New England region can influence movement from the NAIA to Division III. While geography may not discourage college movement, some regions have 
a higher likelihood of movement than others. As an example, Great Lakes region schools have greater odds (1.46 more likely) to move from the NAIA to Division III opposed to Division II (47\% less likely). In comparison, Southeast region schools are 1.76 times more likely to join Division II and 36\% less likely to join Division III. Finally, the Mideast region has greater odds of schools leaving for the NCAA regardless of division. These findings support claims made by university officials from schools proclaiming the lack of opponents in close proximity as a decision for their departure from the NAIA to the NCAA ("SOSU Leaves NAIA for NCAA", 1994; Weaver, 2010). The departure of competitors within a region may pressure decision makers to consider changing affiliations to maintain relationships and rivalries that are part of the organization's identity (Washington, 2004-05).

In relation to religious affiliations, both tables note schools affiliated with Catholicism or Evangelist Protestant denominations are more likely to join the NCAA regardless of division after similar schools move. Mainline Protestant schools, on the other hand, are more likely to transfer to Division III instead of Division II. Potentially, Mainline Protestant schools may have desired a separation from other religious groupings and sought Division III membership. According to Taylor and McKirnan (1984), this process involved adopting characteristics based upon linguistic, cultural or other modifiable dimensions. Thus, Mainline Protestant schools could have molded their culture to match Division III schools for identity enhancement.

The HBCU and women's only institutions also show significant findings in both tables. Both tables suggest HBCUs are more likely to leave the NAIA for the NCAA after other HBCUs depart for the NCAA. However, in terms of significance, HBCUs have 1.72 greater odds to join Division II. These schools continue to maintain the HBCU identity while adopting the characteristics of the division with which the decision makers choose to associate. Thus, HBCUs pressure one another to act as a collective unit as opposed to an individual nature. Through this collective, HBCUs maintain their race identity while assimilating within their new group setting (Hogg \& Terry, 2000; Taylor \& McKirman, 1984). Similar to HBCUs, women's only colleges likely saw themselves as a collective group and pressured each other to maintain this identity when considering reclassification from the NAIA to the NCAA (Hogg \& Terry, 2000; Taylor \& McKirman, 1984). As such, Model Three shows women's only colleges have 1.18 greater odds to join Division II instead of staying in the NAIA.

For schools designated as private, both tables show the private school characteristic has no significant effect on the likelihood of movement to either division. The lack of significance for the private school identity may relate to the high frequency of private schools contained in the sample (76.2\% of observations). Rao et al. (2000) suggested if a social characteristic is prevalent among group members, the probability of defection from an in-group to an out-group would significantly decrease. Because of the high concentration of private schools associated with the NAIA, if a private school chooses to depart the NAIA (i.e., the in-group) for Division II or III (i.e., the out-groups), other private schools will not be affected by defectors. Thus, the private school identity does not create pressure for NAIA members to consider reclassification.

During its early success, the NAIA membership focused exclusively on smaller schools. Due to this focus, it is not surprising to see large or very large schools more 
likely to transition from the NAIA to Division II when similar size schools moved but did not transition to Division III since the NCAA was developed and traditionally known to accommodate larger schools (Falla, 1981; Stooksbury, 2010; Wilson, 2005). These larger schools may choose Division II to associate with other larger schools and the opportunity to join Division I in the future to further establish their respective identities in the field. However, Table 3 also notes small or very small schools are more likely to transfer to Division II in relation to other smaller schools opposed to Division III, which was not significant. These results are interesting as Division III is considered the division to support smaller schools (Washington, 2004-05; Wilson, 2005). However, many former NAIA members classified as small schools joined Division II instead of Division III. Collectively, these schools may have based their decision to join Division II over III on financial support ("Football Rights Fees Announced", 1976; Washington, 2004-05) or the different rules in the two divisions. For example, the distribution of financial aid to student-athletes at Division II schools is equivalent to a set number of full scholarships while Division III prohibits any financial aid based on athletics ("Divisional Differences and the History", n.d.). Many smaller institutions could have collectively reviewed the benefits and the regulations and determined what would be in their best interests for their respective schools. Nonetheless, a university's divisional alignment decision may depend upon each school's budgetary concerns, the vision from decision makers, and the benefits received from the NCAA.

The final identity is the sponsorship of revenue-generating sports programs. One can argue certain sports can influence schools to consider movement based on moves by rival firms. However, both tables show football and men's basketball do not have a substantial effect on the movement to either division. This result is surprising as many reclassification decisions have been based on football and men's basketball ("SD Mines, BHSU to Move", 2010; "SOSU Leaves NAIA For", 1994). Instead, schools sponsoring women's basketball show a likelihood of movement to Division II opposed to Division III. Although a nonrevenue generating sport (Falla, 1981), the growth of women's basketball since the implementation of Title IX could have influenced schools to reclassify to receive funding to sponsor the sport.

\section{Conclusion}

Since the creation of Divisions II and III in 1973, the NCAA has foreseen a substantial growth in membership, while depleting counts can be observed for the NAIA (Wilson, 2005). Similar to Washington (2004-05) and Smith et al. (2013), the current study notes universities affiliated with the NAIA faced significant pressure from their peers to leave the association for the NCAA. Furthermore, the more characteristics that schools shared with NAIA defectors created an identity-discrepant cue and encouraged schools to conduct a social mobility strategy. The present research also provides social identities influence organizations in their development of a strategic plan when faced with mimetic pressure to make significant changes. In terms of college movement, schools considering a reclassification would be wise to explore the strategies of similar institutions before engaging in a social mobility strategy. Although the benefits received from NCAA affiliation can be enticing, university officials could possibly put their institution at risk due to the significant costs of movement if placed in the wrong division. 
While the current study argues firms are influenced by institutions possessing similar characteristics, the study also notes each school's motivations are independent of one another. Although this study monitors the activity of schools changing affiliations, the study does not provide individual stakeholder views or motivation from each university considering reclassification. To acquire these motivations, qualitative methodologies such as case studies or historical analysis would need to be used (e.g., Dwyer et al., 2010; Weaver, 2010).

The present study also notes firms should use caution when attempting to acquire legitimacy through social mobility. The motivations for movement, as well as the strategic changes by the NAIA and the NCAA, led both organizations to alter their respective identities within the organizational field. Specifically, the creation of identity-discrepant cues by NAIA defectors caused a significant change in the rationalized myths of the organizational field. While the NCAA benefitted from the change, the intercollegiate athletic field overall has suffered from the mobility. Thus, the current study encourages firms to identify potential ramifications to the organizational field when conducting a social mobility strategy.

Organizations also have the power to disassociate themselves from their current group setting should they feel another association aligns better with their goals and objectives. Such membership rules and norms can be used to delineate the exclusionary boundaries of institutional membership and the space that members can operate or use. The present study argues associations should restrict admission of firms if legitimacy is positively related to the group's exclusivity but to embrace a larger set of variable members if cultural mechanisms establish standards that are not coercive or likely to impose mimetic pressures to comply with other industry standards. In addition, the need for external resources causes firms to quickly adopt the rules prescribed by the leading actors within the organizational field.

The present research further extends the social identity literature by noting the mimetic pressure to gain legitimacy in an organizational field can influence firms to engage in social mobility. While Rao et al. (2000) argued movement can be influenced by the focal organization's affiliations to group members and defectors, social mobility alone may not help a firm obtain legitimacy. Instead, institutions will continuously implement strategies to establish and maintain their legitimacy within their respective institution. These strategies are conducted to influence the mobility of firms to their association using an organization's social identity as a means to attract new members. This study argues a firm's social mobility strategy may be influenced more by the social identity of the affiliation itself opposed to the individual firms.

The present study also contributes to the college movement literature through the use of sports as an identity. Specifically, the present research shows sport offerings can influence a university's social mobility strategy since some schools hold specific teams to a higher regard. Furthermore, this study shows the choice of NCAA division is highly dependent on the individual characteristics of each university. Wilson (2005) noted the NAIA closely mirrored Division III based on similar policies and the number of schools leaving the NAIA for Division III. However, the present research shows potential movement from the NAIA to the NCAA varies based on the social identities of each university. Thus, university decision makers should analyze those factors and prioritize what is best for their organization before considering a move. 
From a practical standpoint, the results can provide both the NAIA and NCAA critical information regarding both the strength and weaknesses of their respective membership distributions. For the NAIA, certain identities are shown to be more prominent among their membership. As such, the NAIA can focus their efforts toward the recruitment of new schools possessing these identities as well as the framework to develop strategies to maintain these members. For example, the NAIA could look to recruit new members found in the Plains region, where movement occurs less frequently in comparison with the other regions. Similar to Smith et al.'s (2013) recommendation, the NAIA can determine competitive advantages for schools in that area that benefit both the athletic department and the university. The NAIA should also consult with current members that possess identities with an increased likelihood of movement to determine and develop strategies the association could provide to help recruit new and maintain current members. Finally, the NAIA should be proactive with members sharing a higher chance of reclassification. The organization can work with these schools to create mechanisms to encourage member schools to stay with the NAIA and develop the school's social identity within the organizational field. Through this process, both the school and the NAIA itself may be able to remove its current identity as a small school organization (Washington, 2004-05).

For the NCAA, the present research provides areas where the NCAA can tailor their transition program for new members. The transition process is unique for each school and having information on the type of school joining the NCAA could help the firm provide vital information to make the process run smoothly. These improvements can include information on compliance concerns, number of sports programs offered, and if athletic scholarships are offered. Furthermore, the NCAA can educate university officials about the potential ramifications of movement by acknowledging the increased revenue opportunities and increased costs. Prior research has noted reclassifications may not result in a significant positive increase in tangible benefits such as alumni donations, enrollment, or game attendance (Tomasini, 2005). However, intangible benefits such as alumni support or increased university recognition can be achieved by reclassification (Dwyer et al., 2010; Weaver, 2010).

Finally, future research can apply the likelihood of movement model to schools moving within the NCAA itself. Specifically, it can explore if identity discrepant cues exist for schools to consider movement between divisions and/or between conferences. The model could also be adjusted to incorporate an additional control variable to monitor the movement of former NAIA members moving within the NCAA. Future works can also determine the likelihood of reverse movement such as a return to a smaller division (i.e., Division I-FCS to Division II; Division II to Division III) or a reclassification from the NCAA to the NAIA. Recent examples of this movement include Centenary College of Louisiana reclassifying from Division I to Division III in 2011 (Bathe, 2011) and West Virginia Tech University returning to the NAIA in 2006 after joining the NCAA in 1994 (Keenan, 2006).

Future studies in college movement could also apply Washington and Patterson's (2011) recommendations for isomorphism studies in sport management to show if organizations are successful after responding to pressure. While the college movement literature has explored probabilities for movement, few studies have explored methods to estimate the quantity and duration of a potential 
reclassification effect. To review this phenomenon, future works should analyze the potential benefits universities expect to receive after joining the NCAA including increases in applications, enrollment, and overall support (Dwyer et al., 2010; Weaver, 2010). The methodology could be similar to studies reviewing increases in applications after sporting success (Mixon \& Hsing, 1994; Mixon \& Ressler, 1995; Mixon, Trevino, \& Minto, 2004; Pope \& Pope, 2009). The results found from a reclassification effect study could curtail university officials to contribute scarce resources for minimal gains.

\section{Notes}

1. Smith et al. (2013) collected the membership list from Chad Waller and the NAIA Membership Services Department. This study used the same list and would like to thank Mr. Waller and his staff for their help in providing the NAIA membership for the time period.

2. Several variables were removed from each model due to their respective observation frequencies. For example, the sample does not include any schools moving from the NAIA to Division III located in the Rocky Mountain region (RM). The sample also does not include any schools affiliated with denominations classified as Black Protestant (BL_PROT) or Other Christian (OTH_CHR).

\section{References}

About Carnegie Classification. (n.d.). The Carnegie Foundation for the advancement of teaching. Retrieved from http://classifications.carnegiefoundation.org/.

About IPEDS. (n.d.). Integrated Postsecondary Education Data System. Retrieved from http://nces.ed.gov/ipeds/about/.

Abraham, B., \& Ledolter, J. (2006). Introduction to regression modeling. Belmont, CA: Thomson Brooks/Cole.

Albert, S., \& Whetten, D.A. (1985). Organizational identity. Research in Organizational Behavior, 7, 263-295.

Ashforth, B.E. (2001). Role transitions in organizational life: An identity-based perspective. Mahwah, NJ: Lawrence Erlbaum Associates.

Ashforth, B.E., \& Mael, F. (1989). Social identity theory and the organization. Academy of Management Review, 14, 20-39.

Bachmann, R., \& Inkpen, A.C. (2011). Understanding institutional-based trust building processes in inter-organizational relationships. Organization Studies, 32, 281-301. doi:10.1177/0170840610397477

Backes, B. (2012). Do affirmative action bans lower minority college enrollment and attainment? Evidence from statewide bans. The Journal of Human Resources, 47, 435-455. doi:10.3368/jhr.47.2.435

Bartsch, V., Ebers, M., \& Maurer, I. (2013). Learning in project-based organizations: The role of project teams' social capital for overcoming barriers to learning. International Journal of Project Management, 31, 239-251. doi:10.1016/j.ijproman.2012.06.009

Bathe, J. (2011, February 14). Centenary College basketball: Saying goodbye to the Gentlemen in Division I. Bleacher Report. Retrieved from http://bleacherreport.com/ articles/607241-centenary-college-basketball-saying-goodbye-to-the-gentlemen-indivison-i.

Battilana, J., \& Casciaro, T. (2012). Change agents, networks, and institutions: A contingency theory of organizational change. Academy of Management Journal, 55, 381-398. doi:10.5465/amj.2009.0891 
Boxenbaum, E., \& Jonsson, S. (2008). Isomorphism, diffusion, and decoupling. In R. Greenwood, C. Oliver, K. Sahlin, \& R. Suddaby (Eds.), The Sage handbook of organizational institutionalism (pp. 78-98). Thousand Oaks, CA: Sage Publications. doi:10.4135/9781849200387.n3

Cunningham, G.B., \& Ashley, F.B. (2001). Isomorphism in NCAA athletic department: The use of competing theories and advancement of theory. Sport Management Review, 4, 47-63. doi:10.1016/S1441-3523(01)70069-1

Cunningham, G.B., Sagas, M., \& Ashley, F.B. (2001). Occupational commitment and intent to leave the coaching profession. International Review for the Sociology of Sport, 36, 131-148. doi:10.1177/101269001036002001

DiMaggio, P.J., \& Powell, W.W. (1983). The iron cage revisited: Institutional isomorphism and collective rationality in organizational fields. American Sociological Review, 48, 147-160. doi:10.2307/2095101

Divisional differences and the history of multidivision classification. (n.d.). NCAA.org. Retrieved from http://www.ncaa.org/about/who-we-are/membership/divisionaldifferences-and-history-multidivision-classification.

Dutton, J.E., Dukerich, J.M., \& Harquail, C.V. (1994). Organizational images and member identification. Administrative Science Quarterly, 39, 239-263. doi:10.2307/2393235

Dwyer, B., Eddy, T., Havard, C., \& Braa, L. (2010). Stakeholder perceptions of an athletic program's reclassification from NCAA Division II to NCAA Division I (FCS) membership: A case study. Journal of Issues in Intercollegiate Athletics, 3, 76-97.

Ellemers, N., Spears, R., \& Doosje, B. (1997). Sticking together or falling apart: In-group identification as a psychological determinant of group commitment versus individual mobility. Journal of Personality and Social Psychology, 72, 617-626. doi:10.1037/00223514.72.3.617

Elsbach, K.D., \& Kramer, R.M. (1996). Member's responses to organizational identity threats: Encountering and countering the Business Week Rankings. Administrative Science Quarterly, 41, 442-476.

Ertug, G., \& Castellucci, F. (2013). Getting what you need: How reputation and status affect team performance, hiring, and salaries in the NBA. Academy of Management Journal, 56, 407-431. doi:10.5465/amj.2010.1084

Falla, J. (1981). NCAA: The voice of college sports. Mission, KS: National Collegiate Athletic Association.

Fink, J.S., Parker, H.M., Brett, M., \& Higgins, J. (2009). Off-field behavior of athletes and team identification: Using social identity theory and balance theory to explain fan reactions. Journal of Sport Management, 23, 142-155.

Football rights fees announced for 1976. (1976, April 15). The NCAA News, 13(5), pp. 3.

Fulks, D. (2014). 2004-2013 NCAA Division I Intercollegiate Athletics Programs Report. Indianapolis, IN: National Collegiate Athletic Association., Retrieved from http://www. ncaapublications.com/productdownloads/D1REVEXP2013.pdf.

Getz, M., \& Siegfried, J. (2010). What does intercollegiate athletics do to or for colleges and universities? (Working Paper No. 10-W05). Retrieved from http://vanderbilt.edu/ econ/ wparchive/workpaper/vu10-w05.pdf.

Greenwood, R., Oliver, C., Suddaby, R., \& Sahlin-Andersson, K. (2008). Introduction. In R. Greenwood, C. Oliver, R. Suddaby, \& K. Sahlin-Andersson (Eds.), Handbook of organizational institutionalism (pp. 1-46). London, England: Sage Publications. doi:10.4135/9781849200387.n1

Halevy, N., Weisel, O., \& Bornstein, G. (2012). "In-group love" or "out-group hate" in repeated interaction between groups. Journal of Behavioral Decision Making, 25, 188-195. doi:10.1002/bdm.726

Heere, B., \& James, J.D. (2007). Stepping outside the lines: Developing a multi-dimensional team identity scale based on social identity theory. Sport Management Review, 10, 65-91. doi:10.1016/S1441-3523(07)70004-9 
Hogg, M.A., \& Terry, D.J. (2000). Social identity and self-categorization processes in organizational contexts. Academy of Management Review, 25, 121-140.

Jackson, L., Sullivan, L., Harnish, R., \& Hodge, C. (1996). Achieving social identity: Social mobility, social creativity and permeability of group boundaries. Journal of Personality and Social Psychology, 70, 241-254. doi:10.1037/0022-3514.70.2.241

Kahn, L.M. (2007). Markets: Cartel behavior and amateurism in college sports. The Journal of Economic Perspectives, 21, 209-226. doi:10.1257/jep.21.1.209

Katz, M.S. (1990). Coach John B. McLendon Jr. and the integration of intercollegiate and professional athletics in post-World War II America. Journal of American Culture, 13(4), 35-39. doi:10.1111/j.1542-734X.1990.00035.x

Katz, M.S., \& McLendon, J.B. (1988). Breaking through: The NAIA and the integration of intercollegiate athletics in post-World War II America. Kansas City, MO: National Association of Intercollegiate Athletics.

Keenan, S. (2006, January 15). WVU Tech to join the NAIA. The Register-Herald. Retrieved from http://www.victorysportsnetwork.com/article/1305.php.

Laband, D.N., \& Lentz, B.F. (2004). Do costs differ between for-profit and not-forprofit producers of higher education? Research in Higher Education, 45, 429-441. doi:10.1023/B:RIHE.0000027394.33115.71

Land, C.B. (1977). A history of the National Association of Intercollegiate Athletics. (Unpublished doctoral dissertation). University of Southern California, Los Angeles, CA.

Maddala, G.S. (1983). Limited-dependent and qualitative variables in econometrics. Cambridge: Cambridge University Press. doi:10.1017/CBO9780511810176

Mael, F., \& Ashforth, B.E. (1992). Alumni and their alma mater: A partial test of the reformulated model of organizational identification. Journal of Organizational Behavior, 13, 103-123. doi:10.1002/job.4030130202

Mason, C.H., \& Perreault, W.D. (1991). Collinearity, power, and interpretation of multiple regression analysis. JMR, Journal of Marketing Research, 28, 268-280. doi: $10.2307 / 3172863$

Meyer, J.W., \& Rowan, B. (1977). Institutionalized organizations: Formal structure as myth and ceremony. American Journal of Sociology, 83, 340-363. doi:10.1086/226550

Mixon, F.G., \& Hsing, Y. (1994). The determinants of out-of-state enrollments in higher education: A tobit analysis. Economics of Education Review, 13, 329-335. doi:10.1016/ S0272-7757(05)80056-1

Mixon, F.G., \& Ressler, R.W. (1995). An empirical note on the impact of college athletics on tuition revenues. Applied Economics Letters, 2, 383-387. doi:10.1080/758518995

Mixon, F.G., Trevino, L.J., \& Minto, T.C. (2004). Touchdowns and test scores: Exploring the relationship between athletics and academics. Applied Economics Letters, 11, 421-424. doi:10.1080/1350485042000201906

O'Brien, D., \& Slack, T. (2003). An analysis of change in an organizational field: The professionalization of English Rugby Union. Journal of Sport Management, 17, 417-448.

Patterson, K.D.W., Cavazos, D.E., \& Washington, M. (2014). It does matter how you get to the top: Differentiating status from reputation. Administrative Sciences, 4, 73-86. doi:10.3390/admsci4020073

Pope, D.G., \& Pope, J.C. (2009). The impact of college sports success on the quantity and quality of student applications. Southern Economic Journal, 75, 750-780.

Pratt, M.G., \& Foreman, P.O. (2000). Classifying managerial responses to organizational identities. Academy of Management Review, 25, 18-42. 
Rao, H., Davis, G.F., \& Ward, A. (2000). Embeddedness, social identity, and mobility: Why firms leave the NASDAQ and join the New York Stock Exchange. Administrative Science Quarterly, 45, 268-292. doi:10.2307/2667072

Rao, H., Monin, P., \& Durand, R. (2003). Institutional change in Toque Ville: Nouvelle Cuisine as an identity movement in French Gastronomy. American Journal of Sociology, 108, 795-843. doi:10.1086/367917

Schneiberg, M., \& Lounsbury, M. (2008). Social movement and institutional analysis. In R. Greenwood, C. Oliver, K. Sahlin, \& R. Suddaby (Eds.), The Sage handbook of organizational institutionalism (pp. 650-672). Thousand Oaks, CA: Sage Publications. doi:10.4135/9781849200387.n28

Schroeder, L.D., Sjoquist, D.L., \& Stephan, P.E. (1986). Understanding regression analysis. Beverly Hills, CA: Sage Publications.

Mines, S.D. BHSU to move from NAIA to NCAA Division II. (2010, July 13). Yankton Daily Press \& Dakotan. Retrieved from: http://www.yankton.net/sports/ article_f61812fb53ed-528e-9f8c-f90b66c90646.html.

Smith, J. (2011). The antecedents and consequences of intercollegiate athletic association change of colleges and universities in Canada and the United States. (Unpublished Doctoral dissertation) University of Alberta, Edmonton, Alberta, Canada.

Smith, J. D., Soebbing, B. P., \& Washington, M. (2015). Motivations for changing athletic associations: An athletic department's perspective. Journal of Contemporary Athletics, 9, 117-132.

Smith, J., Williams, D., Soebbing, B.P., \& Washington, M. (2013). The influence of a university's social identity on changing athletic affiliations. Journal of Issues in Intercollegiate Athletics, 6, 22-40.

Smith, R.A. (1988). Sports and freedom. Oxford, England: Oxford University Press.

SOSU leaves NAIA for NCAA Division II. (1994, December 23). The Durant Daily Democrat, Section A, pp. 1-A.

Southall, R.M., \& Nagel, M.S. (2008). A case study analysis of NCAA Division I women's basketball tournament broadcasts: Educational or commercial activity? International Journal of Sport Communication, 1, 516-533.

Southall, R.M., Nagel, M.S., Amis, J.M., \& Southall, C. (2008). A method to march madness? Institutional logics and the 2006 National Collegiate Athletic Association Division I men's basketball tournament. Journal of Sport Management, 22, 677-700.

Steensland, B., Park, J.Z., Regnerus, M.D., Robinson, L.D., Wilcox, W.B., \& Woodberry, R.D. (2000). The measure of American religion: Toward improving the state of the art. Social Forces, 79, 291-318. doi:10.1093/sf/79.1.291

Stooksbury, D. (2010). National title: The unlikely tale of the NAIB tournament. Bradenton Beach, FL: Higher Level Publishing.

Strang, D., \& Soule, S.A. (1998). Diffusion in organizations and social movements: From hybrid corn to poison pills. Annual Review of Sociology, 24, 265-290. doi:10.1146/ annurev.soc.24.1.265

Suchman, M.C. (1995). Managing legitimacy: Strategic and institutional approaches. Academy of Management Review, 20, 571-610.

Suddaby, R., Elsbach, K.D., Greenwood, R., Meyer, J.W., \& Zilber, T.B. (2010). Organizations and their institutional environments-bringing meaning, values, and culture back in: Introduction to the special research forum. Academy of Management Journal, 53, 1234-1240. doi:10.5465/AMJ.2010.57317486 
Tajfel, H., \& Turner, J.C. (1985). The social identity theory of intergroup behavior. In S. Worchel \& W.G. Austin (Eds.), Psychology of intergroup relations (2nd ed., pp. 7-24). Chicago, IL: Nelson-Hall.

Taylor, D.M., \& McKirnan, D.J. (1984). A five-stage model of intergroup relations. British Journal of Social Psychology, 23, 291-300. doi:10.1111/j.2044-8309.1984.tb00644.x

Tolbert, P.S., \& Zucker, L.G. (1983). Institutional sources of change in the formal structure of organizations: The diffusion of civil service reforms 1880-1935. Administrative Science Quarterly, 23, 22-39. doi:10.2307/2392383

Tomasini, N.T. (2005). An assessment of the economic differences associated with reclassification to NCAA Division I-AA. Sport Marketing Quarterly, 14, 7-16.

Turner, J.C. (1985). Social categorization and the self-concept: A social cognitive theory of group behavior. In E.J. Lawler (Ed.), Advances in group processes (2nd ed., pp. 77-122). Greenwich, CT: JAI Press.

Washington, M. (1999). The role of status and institutional pressure on organizational change: Sports as a visibility strategy of colleges and universities 1893-1996. (Unpublished doctoral dissertation). Northwestern University, Evanston, IL.

Washington, M. (2004). Field approaches to institutional change: The evolution of the National Collegiate Athletic Association 1906-1995. Organization Studies, 25, 393-414. doi:10.1177/0170840604040042

Washington, M. (2004-05). Declining legitimacy and social mobility. International Studies of Management \& Organization, 34(4), 32-51.

Washington, M., \& Patterson, K.D.W. (2011). Hostile takeover or joint venture: Connections between institutional theory and sport management research. Sport Management Review, 14, 1-12. doi:10.1016/j.smr.2010.06.003

Washington, M., \& Ventresca, M.J. (2008). Institutional contradictions and struggles in the formation of US collegiate basketball, 1880-1938. Journal of Sport Management, 22, 30-49.

Washington, M., \& Zajac, E.J. (2005). Status evolution and competition: Theory and evidence. Academy of Management Journal, 48, 282-296. doi:10.5465/AMJ.2005.16928408

Weaver, A. (2010). Reevaluating prestige: The influence of history on the decision to reclassify to Division I: A case study. Journal of Issues in Intercollegiate Athletics, 3, 131-153.

Williams, D.P. (2014). An analysis of a university reclassification effect on applications following a move to a new intercollegiate athletic association. (Unpublished doctoral dissertation). Louisiana State University, Baton Rouge, LA.

Wilson, J.R.M. (2005). The history of the National Association of Intercollegiate Athletics: Competition, tradition, character. Monterey, CA: Coaches Choice. 